\title{
Cars, conflict and community severance
}

Laura Vaughan, Paulo R Anciaes, Jennifer S Mindell

\begin{abstract}
'Community severance', is the deterrent effect that motor vehicles or road or rail infrastructure, can have on people walking along or across busy roads. Such barriers can interfere with individuals' ability to access the goods, services, and people they need for a healthy life, as was shown by Appleyard and Lintell in 1972. Many publications assert that community severance affects health; while plausible, no study has examined this explicitly. This chapter summarizes early studies of severance and existing knowledge of the pathways through which community severance could affect health. Heavy and/or fast motor traffic leads to detours for pedestrians and reduces the pleasantness and safety of walking and cycling, with increased injury risk and air and noise pollution. Active travel is then replaced by sedentary modes, reducing physical activity and independent mobility, especially for the young and old, those with mobility impairments, and individuals for whom public transport is unaffordable or unavailable. The use of streets as social spaces is a key feature of a healthy community; adverse effects on individuals' health of fewer social contacts are well-recognized.

This chapter then describes a research project undertaken in England to develop tools to assess and value the effects of community severance. Tools include: participatory mapping; a pen-and-paper questionnaire for local residents (plus guidance on running and analyzing a survey); analysis of street video survey data; evaluation of the pedestrian environment; space syntax and walkability models; a community severance index; and a valuation tool. We showed that people living near busy roads prefer signalized crossings to underpasses and pedestrian bridges, and fewer lanes and slower motor traffic speeds. Busy, polluted roadways deter people, particularly older people from using them, even if they provide many local shops and services, although the impact on people's health and wellbeing lessened with distance lived from the road. Recognizing differences between 'roads' and 'streets', equivalent to 'link' and 'place', urban designers and planners have important roles to play in shaping the environment to encourage walking as part of people's daily activities.
\end{abstract}

\section{Introduction}

This chapter describes the results of a large research project into Street Mobility and Network Accessibility. This took place at UCL (University College London) between 2014 and 2017, with the aim of developing tools to assess and value the effects of busy roads on people living in its vicinity, or, as it is formally termed, 'community severance'. Our research was inspired by the influential work of Appleyard and colleagues (Appleyard and Lintell 1972, Appleyard et al. 1981), especially their findings regarding the impact of road traffic speed or volume on people's ability to make social ties with other people in their vicinity. Our project also built on many years' research into community severance from a public health perspective, which found that traffic speed and volume reduces physical activity, social contacts, children's play, and access to goods and services (see review in Mindell and Karlsen 2012).

Please contact the first author if you wish to quote from the text. The published version is as follows: 
Liepmann used the term 'severance' in 1944, commenting on the effects on communities of 'severance of dwelling and work-place' (Liepmann, 1944). In the UK, Lassière (1976), used 'severance' more specifically to describe the impact of transport infrastructure or major roads on people's perceptions and behavior in a study for the UK Department of the Environment. Lassière's survey of London residents of sites near motorways found that the presence of major arterials results in people changing their walking behavior; shifting the local focus of their neighborhood away from the motorway, compared with those living near quiet sites. His findings are analogous to Appleyard and Lintell's findings (Appleyard and Lintell, 1972): the number of sites included within 'their neighborhood' on the other side of the motorway was lower than in control sites; reduced further over time; and lessened the farther people lived from the motorway.

By 1983, the UK Department of Transport defined 'community severance' from trunk roads [arterials] as "the separation of residents from facilities and services they use within their community, from friends and relations and, perhaps, from place of work as a result of changes in road patterns and traffic levels" (DOT 1983, Part B 4.1.1). More recently, McAndrews and Marshall (2018) found, perhaps surprisingly, that arterials with intersections ('nodes') where multiple commercial land uses (shops, restaurants, bars, for example) co-exist on a number of streets are considered vibrant and contribute to the neighborhood livability, even though these often had the highest motorized traffic levels, provided there were adequate sidewalks, lighting and transit access. Another type of arterial that was related to livability were those which are quiet and calm, clean with no trash, cycle friendly, and had trees. Even where motor traffic levels or speeds were lower, arterials that lacked features such as sidewalks, were not considered pedestrian or cycle friendly, or had trash with perceptions of risk from crime, were likely to have a negative impact on neighborhood livability. Interestingly, the most and least livable factors often coexisted on the same arterials. Thus, the factors associated with neighborhood livability and motorized traffic, and the ways people adapt to arterials, are more nuanced than is first imagined.

While severance from roads has frequently been claimed to affect health, Mindell and Karlsen's systematic review from 2012 mentioned above found almost no work that considered the effects of community severance on health over time. Their conclusion was that a causal relationship was plausible, through the various pathways shown in Figure 1, but that there was no direct evidence. It should be noted that 'no evidence of an effect', i.e. no-one has examined it in practice, is not the same as 'evidence of no effect'. There is plenty of empirical evidence for each of the solid arrows in Figure 1. Heavy and/or fast motor traffic leads to detours to walking routes (Hine 1996) and reduces the perceived pleasantness and safety of walking and cycling, due to risks of injury and from air and noise pollution (Bornioli et al. 2018). The power of motor vehicles to 'push' pedestrians and cyclists off the road has several consequences, illustrated in our figure, including reductions in physical activity because walking or cycling for travel - or leisure - are replaced by sedentary travel modes or activities (Giles-Corti and Donovan 2003). There is also a loss of independent mobility, especially for those unable to drive, including the young (Smith and Gurney 1992, Hüttenmoser 1995, Rothman et al. 2015), those with age-related and other impairments (Bascom and Christensen 2017, Shaw et al. 2012) and individuals for whom public transport is unaffordable or unavailable (Laverty et al. 2018, Barnes et al. 2016).

Please contact the first author if you wish to quote from the text. The published version is as follows: 


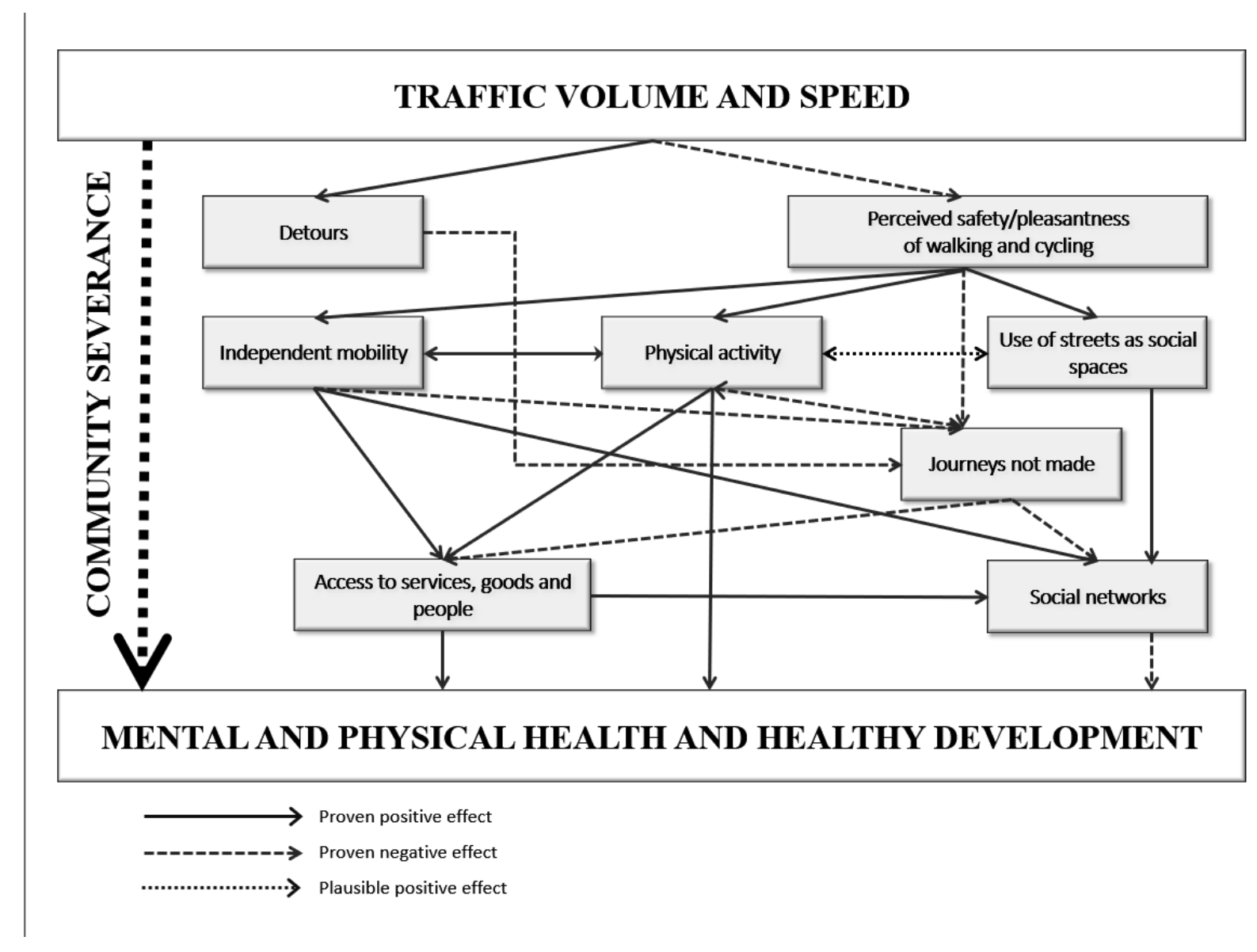

Figure 1: Systems analysis of routes through which community severance from busy roads could impact negatively on health. Diagram redrawn from the original in Mindell and Karlsen (2012)

The use of streets as social spaces is a key but under-recognized feature of a healthy community. Building on the pioneering work by Berkman and Syme (1979), the adverse effects on health, behaviors, and mortality of fewer social contacts is now well-recognized (Mindell and Karlsen 2012). Holt-Lunstad and colleagues (2010) have demonstrated the large beneficial impact that social relationships have on mortality, of a similar magnitude to the benefits of stopping smoking. It is therefore plausible to infer that the quality of the street environment can itself improve social connections, as indeed was first proposed by Appleyard and Lintell, with the latest research suggestive of similar results; whether a direct relationship, such as social isolation corresponding to greater mortality during a heatwave (Keller 2014), or an indirect relationship, such as an reduced active transport environment corresponding to greater morbidity (Mouratidis 2018, Berke et al. 2007).

\section{The study}

Because motor vehicles deter people from walking along or across busy roads, they also interfere with individuals' ability to access the goods, services, and people they need for a healthy life. Busy roads also reduce the amenity value of streets as social spaces and, as Appleyard et al emphasized, the amount and quality of neighboring (Appleyard et al., 1981, p. 35). Barriers to active living 
particularly affect children, who are denied freedom to explore, play, and travel without adult supervision (Hüttenmoser 1995, Shaw et al. 2013), and older people, whose slower walking speeds limit their ability to cross roads (Asher et al. 2012, Duim et al. 2017, Shaw et al. 2012). In both cases, this reduces independence. Despite this, there has been a lack of tools to identify, assess, and study community severance caused by busy roads.

Mindell and Karlsen's review found that there was little evidence of the effects of community severance on mental or physical health. The Street Mobility study reported here aimed to start to fill that gap. In order to address this lack of tools and due to the complexity of the research and planning settings in which they need to be employed, we aimed to develop a suite of evidence-based tools to measure and value the negative effects of busy roads on local residents. ${ }^{1}$ The project brought together experts from a variety of disciplines - including public health, transport, anthropology, geography, statistics, and urban design - to measure severance through a variety of methods: participatory mapping; video surveys; street audits; a walkability model; a survey on local mobility, health, and wellbeing; and a stated preference survey. These methods were developed, refined, then tested in four consecutive case study areas around busy urban roads in England: two in London and two outside London (one in a coastal town and the other in one of England's largest cities). Table 1 describes their location. The development of the methods and their application in one of those areas (Finchley Road, in North London) is documented elsewhere, demonstrating validation by triangulating findings from different data sources (Mindell et al. 2017). In this chapter we describe what the methods add to the theme of conflict discussed in this book section.

Table 1. Location of the four case studies

\begin{tabular}{|l|l|l|l|}
\hline $\begin{array}{l}\text { Case } \\
\text { study }\end{array}$ & Location & $\begin{array}{l}\text { Principal street } \\
\text { studied }\end{array}$ & Purpose of case study \\
\hline 1 & $\begin{array}{l}\text { Woodbury Down, } \\
\text { Hackney, London }\end{array}$ & Seven Sisters Road & Development of tools \\
\hline 2 & Swiss Cottage, London & $\begin{array}{l}\text { Finchley Road } \\
\text { (Figures 5 \& 6) }\end{array}$ & $\begin{array}{l}\text { Testing of amended } \\
\text { tools }\end{array}$ \\
\hline 3 & Southend-on-Sea, Essex & Queensway & Refinement of tools \\
\hline 4 & $\begin{array}{l}\text { Birmingham, West } \\
\text { Midlands }\end{array}$ & Stratford Road & $\begin{array}{l}\text { Testing of final version } \\
\text { of toolkit }\end{array}$ \\
\hline
\end{tabular}

Aspects of the conflict created by busy traffic on streets were revealed in the results of the video surveys we conducted across our four case studies. Data were collected for 16 hours on a weekday during the school term, with the first 15 minutes of each hour analyzed for motor traffic flows, pedestrian flows, pedestrian crossing ratios, pedestrian crossing routes. One of the objectives of this method was to analyze pedestrian road crossing behavior (where, how, and when pedestrians cross the road). The results of the video survey of case 1, Seven Sisters Road in London, were possibly the most striking of the four cases, given that it has almost no pedestrian destinations other than bus

\footnotetext{
${ }^{1}$ More details of the project, publications, our toolkit to measure severance, and associated documents can be found at www.ucl.ac.uk/street-mobility. The toolkit, which can be downloaded freely along with other resources from www.ucl.ac.uk/street-mobility/toolkit, can be used by community groups, local government, or researchers.
}

Please contact the first author if you wish to quote from the text. The published version is as follows: Vaughan, L., Anciaes, P., \& Mindell, J. (2020). Chapter 9. "Cars, conflict and community severance". In B. Appleyard (Ed.), Livable Streets 2.0: Elsevier, pp. 121-28. 
stops and has a wall separating the sidewalk from the apartment blocks (so there are only a limited number of entrances to the residential area).

In this simplified spatial context, with few reasons to cross other than to go to and from home, it was clear from the observation of the footage in Seven Sisters Road that motor traffic is an obstruction to pedestrians wishing to cross where it is most convenient for them. A large proportion of pedestrians crossed the road at bus stops and at the entrances to the residential area, rather than making a detour of a few meters to cross at road junctions with signalized crossing facilities (Error! Reference source not found.). However, adding a new crossing facility near bus stops is unfeasible due to their proximity to the existing junction, which would lead to delays to car and bus passengers: the improvement of non-motorized forms of mobility can contribute to the deterioration of motorized mobility - transport planners need to determine a trade-off between the two types of mobility.

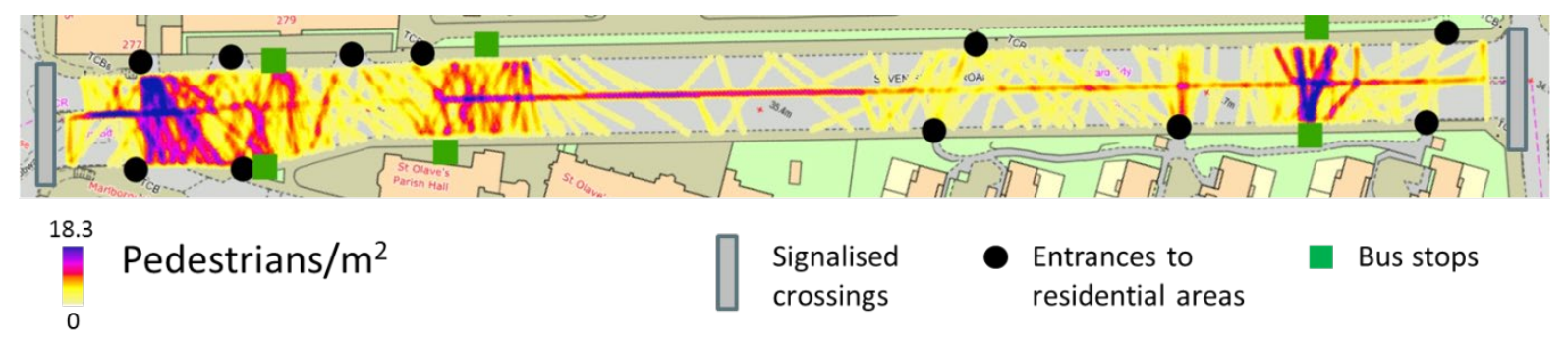

Figure 2: Density of pedestrians crossing a busy road (over a 15-hour period)

In practice, pedestrians are most likely to lose out when there is a conflict between them and motor vehicles, given the vulnerability of pedestrians, especially those with limited mobility. Clearly, motor vehicles can put pedestrians off from using the road, though the most able pedestrians will still try their luck in crossing when traffic is sparse, risking injury to reach their destination in the most direct manner possible.

Research shows that when faced with a hostile road environment, with a large volume of cars or with cars moving at high speed, some people will choose not to walk and may use cars themselves or choose public transportation. If neither is available, they may suppress some of the trips they would like to make. We confirmed previous research into this subject by using our mobility and health survey at the national level. Compared with people living near quiet roads, the probability that people living near busy roads will walk to a park is $9 \%$ lower; the probability they would go by private car is $2 \%$ higher; and the probability they would not go to a park at all is $8 \%$ higher. Similar differentials were found for all other destinations presented in the survey (shops, supermarkets, community centers, health centers, pharmacies, and cafés).

Other people living near busy roads might not actually stop walking completely but will instead choose alternative destinations (which may not be their preferred destination) or alternative walking routes (which may be longer than the routes along or across the busy road). These routes may take them away from exactly the type of roads where they might meet other people - namely busy shopping streets or lively community areas - if they feel vulnerable to, or dislike, heavy traffic.

Please contact the first author if you wish to quote from the text. The published version is as follows: 
The effect of high volumes or speeds of motorized traffic on the mobility of pedestrians may be assessed by measuring discrepancies between observed pedestrian flows and the flows that would be expected considering the walking trips generated by the main local pedestrian destinations. We also applied this approach in the area around Seven Sisters Road (case study 1). In such a strippedback context, with few reasons to be walking about other than to/from work or school, the expected walking flows along the busy road and in the surrounding streets can be approximated by collecting data on the number of passengers boarding and alighting buses at each stop, assigning them to homes (assumed to be the origins and destinations of walking trips to bus stops) and reproducing the shortest walking routes from homes to bus stops. It is then possible to calculate the expected flows in all road and streets of the neighborhood (including the busy road) and then compare them with the observed flows, taken from the video survey (see detailed exposition in Anciaes and Jones, 2016).

The results showed that the ratio between the observed and expected pedestrian flows along pedestrian pavements is much lower along the busy Seven Sisters Road (points with traffic volume above 20,000 in the figure below) than in the surrounding minor roads and streets (Figure 3 ). This suggests that some pedestrians use these minor roads and streets rather than walk along the main road.

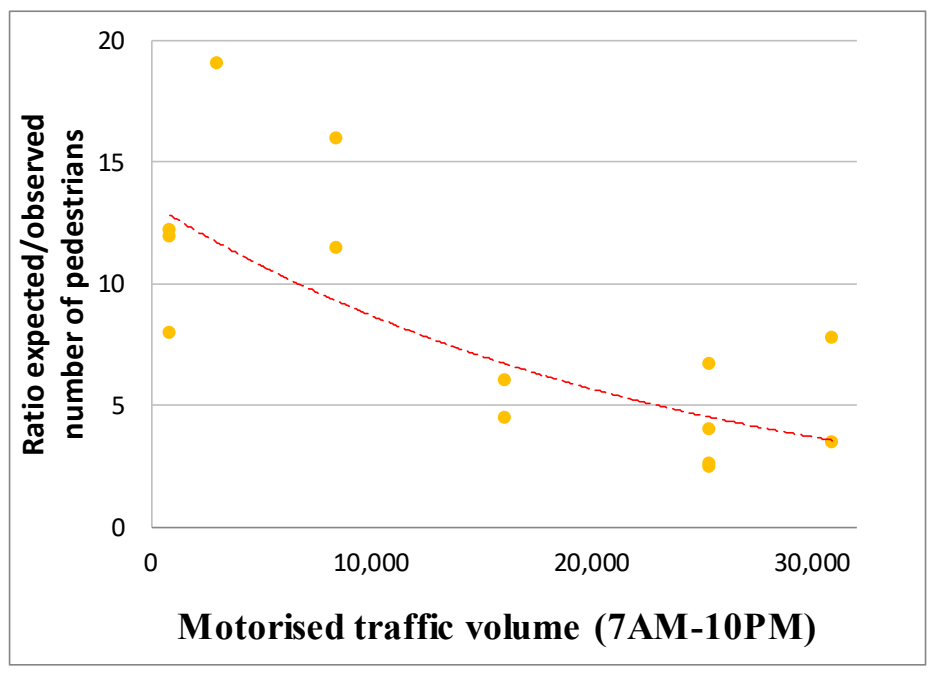

Figure 3: Influence of motorized traffic volume and discrepancies between expected and observed pedestrian flows (over a 15-hour period)

In addition to the video study, we used a stated preference survey to understand what type of road residents would like to have in their local areas. This was administered to 100 participants in each case study to develop cost valuations for different road width, traffic volume and speed, and road crossing options. The results were clear. They showed that residents want to reduce conflicts with motorized vehicles and the power those vehicles have over them when they walk in their local area. Survey participants showed that they prefer roads that have a middle strip that provides extra safety when crossing the road, and traffic moving at lower speeds - although the strength of these two preferences is weaker than the preferences for fewer lanes and less traffic (Anciaes and Jones 2018). Participants also indicated that they prefer to wait at signalized crossings rather than being exposed

Please contact the first author if you wish to quote from the text. The published version is as follows: 
to the inconvenience and possible danger from using crossing facilities such as footbridges and underpasses, let alone the considerable increase in time using such facilities might involve.

The results of our health and wellbeing survey among people living within the four study sites highlighted an important aspect of our findings: around half of people surveyed were affected by traffic, and older people appeared to be affected more (see the development of the questionnaire and its results in Mindell et al. 2017). The impact lessened with distance from the road, but still, the likelihood that busy, polluted roadways deter people from using them, even if they provide many local shops and services, is an important finding. Indeed, the participatory mapping conducted across our case studies bore this out. In case study 2, one of the most heavily trafficked streets in London, participants made comments such as "I hate walking on Finchley Road - even though the pavements are wide it feels dangerous with baby buggies, children on scooters, cyclists and pedestrians all mixed together, you don't hear them coming and the next thing they are rushing past you and you feel as though you could get knocked over." (Mindell et al. 2017). See Figures 4 and 5: Finchley Road with its central reservation, heavy volumes of traffic, and isolation of pedestrians.

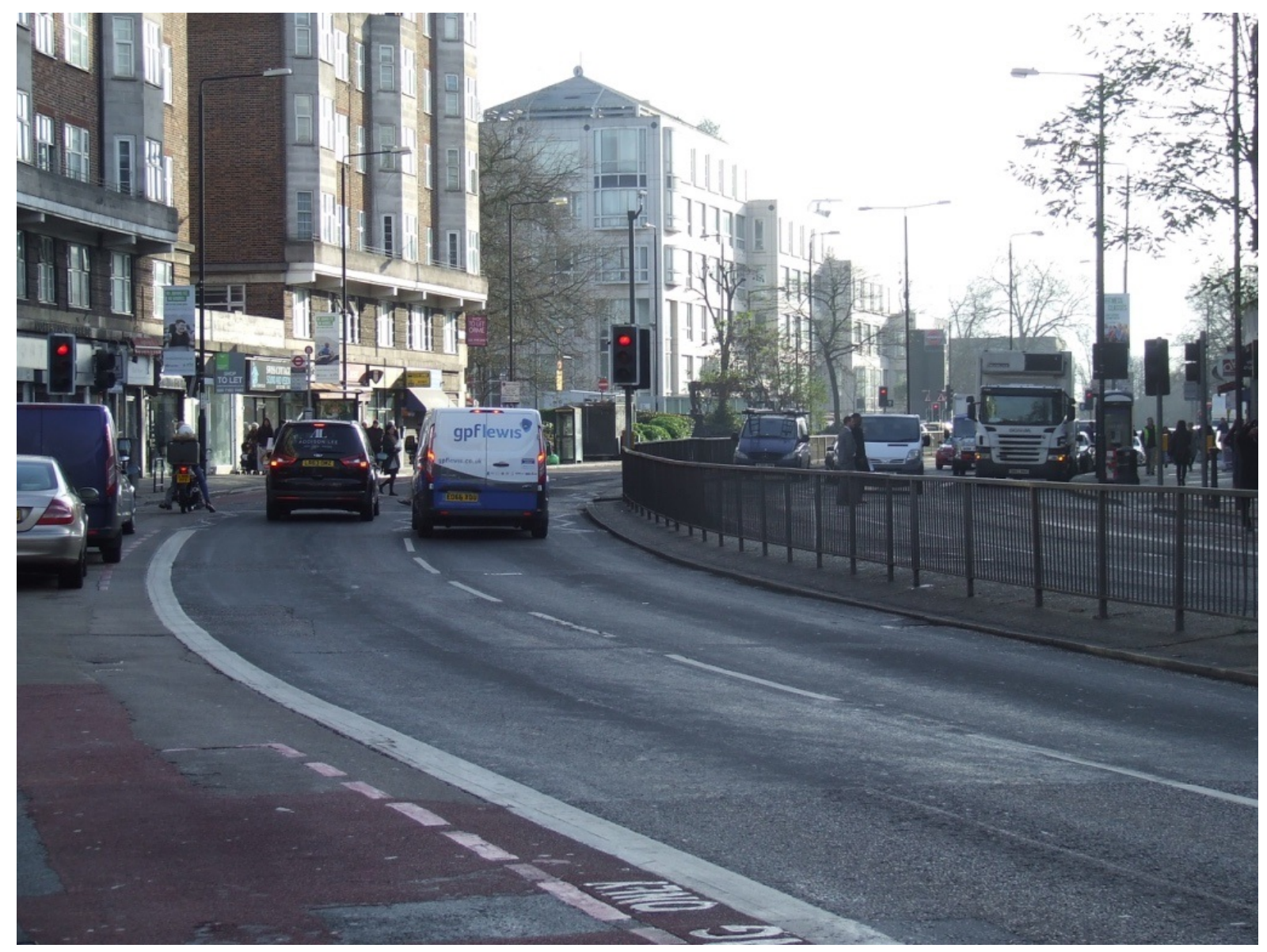

Figure 4: Finchley Road 
Local governments in many countries are starting to respond to pedestrians' needs, with initiatives such as "road diets" (reducing the number of lanes for motorized vehicles); "complete streets" (reallocating road space in favor of non-motorized modes of transport); traffic restriction in city centers and road pricing at entrances to the center; and reduction of speed limits in main roads and creation of "home zones" or $20 \mathrm{mph}$ zones. Transport for London was the first transport authority worldwide to publish its own health action plan (TfL 2014). It now has a focus on "Healthy Streets" (https://healthystreets.com), to incorporate features adding to livability and walkability of streets in all planning and development decisions. Initially employed to reduce air pollution, these policies are increasingly implemented to increase street livability, recognizing that once the direct effects of busy roads have been ameliorated, improving the quality of the street environment itself - the ecology of the street - is important to encourage people to use it for social and economic activities.

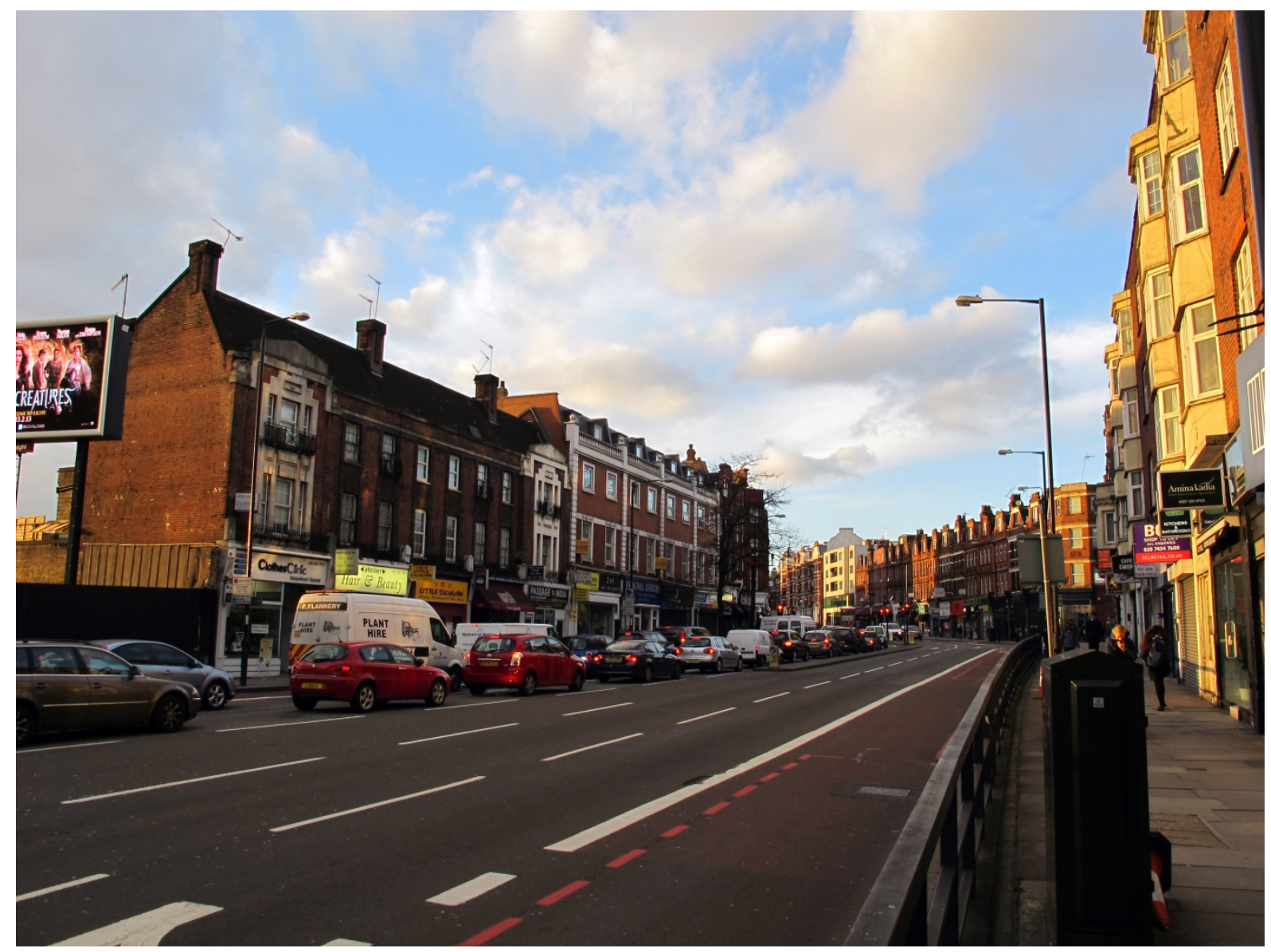

Figure 5: Finchley Road

\section{Designing livable streets}

We have seen that community severance is an issue for both transport planners and public health experts. While Appleyard and Lintell's classic study is commonly considered from the point of view of traffic conflict, their findings have been highly influential in demonstrating the impact high volumes and/or fast motorized transport have on people's use of their local realm, their results regarding the role of urban design in shaping the livability of streets is less well known (Hanna et al. 2011, Boniface et al. 2015). Our research focused on the vital impact that motorized traffic can have 
on roads; in writing on this topic, it is easy to slide between two apparently synonymous terms: streets and roads, but the difference between them is quite profound. Typically, a road is a route, an artery whose primary purpose is to carry motorized traffic. It is difficult to cross, so is difficult to use as a local place. In contrast, a street is constituted by doorways and windows, sometimes simply residential entrances, perhaps with stoops (as in Appleyard's San Francisco, or the famous West Village setting of Jane Jacobs (Palaiologou and Vaughan 2014), but in other cases will be aligned with live uses, whether a corner shop, or complete arrays of shops and businesses. Streets with walkable destinations are more likely to promote walking in the neighborhood in general (Sarkar et al. 2013). In Appleyard's study, the 'Light Street' had so much higher social interaction related both to the low level of traffic but also to a much richer level of detailed architectural description by the street's residents.

In their extended study, the residents of the 'Light street' reported a much larger array of meeting places on the street than those living on the 'Mid street', with almost none reported by the 'Heavy street' residents (Appleyard et al. 1981). Appleyard's study was an important starting point for our own consideration of the urban design characteristics of our case studies. Finchley Road (case study 2) exemplified the cycle of the street's decline from being a tree-lined avenue in the 1930s, with a rich array of local shops, department stores, and businesses, to its widening into an arterial route towards the end of the last century. The consequential increases in traffic and pollution transformed the road from being a place to spend time in to becoming a link to somewhere else (Jones et al. 2007).

The first point is that instead of focusing on the single road and the impact of busy traffic on it, we expanded our study to consider the people and the streets linking to it. This approach was influenced by the space syntax architectural analytical methods used in the urban design part of the study. Space syntax analysis considers the street network as a configuration: as a system of interlinked connections. Thus, we knew from previous such studies that the specific circumstances of Finchley Road are likely to have shaped - and to have been shaped by - its wider context. We therefore considered the connectivity properties of our case studies, by building a large-scale computer model that took account of the street network's relative accessibility, land use diversity, residential population density, and proximity to public transportation set within the wider context of urban London (Dhanani et al. 2017). This allowed us to assess whether there was any relationship between where people walked (or avoided) and where the model predicted they were likely to walk (or avoid).

Our results showed significant and positive associations between the various built environment variables and walking rates (computed by calculating the density of reported walking routes from a large database supplied by London's transport authority). The most important variables were network accessibility (namely, how likely a route was to be used for walking) as well as the diversity of land uses around that route. A key insight in the study was that the greatest impact of community severance is where people would ideally like to be travelling on foot but are most likely to encounter large volumes of motorized traffic. We concluded from this that urban designers and transport planners both have an important role to play in shaping the environment: first to encourage walking to form part of people's daily activities and second to assess where best to improve the road infrastructure to make it easier for people wishing to move around on foot. 


\section{Conclusion}

Our research has found that even in cities such as London, which can boast of high rates of walking and many positive urban design attributes, the effects of busy roads can be much wider and more profound than shaping patterns of interaction amongst its residents. We had previously reviewed the various existing definitions of community severance, which tended to focus on barriers to crossing roads (Mindell and Karlsen 2012, Anciaes 2015). It was clear to us that community severance affects residents of a wider area, not just those living alongside a single road. Like the San Francisco study, busy roads have an impact that can shape behaviors over a long period of time. We therefore produced a new definition of community severance:

"Transport-related community severance is the variable and cumulative negative impact of the presence of transport infrastructure or motorized traffic on the perceptions, behavior, and wellbeing of people who use the surrounding areas or need to make trips along or across that infrastructure or traffic flow." (Anciaes 2015)

The importance of designing livable streets is becoming increasingly a matter of interest for a wide variety of disciplines: for urban designers, in wishing to reshape the public built environment to be inclusive to all; for transport planners, who are placing walking and cycling as modes of transport that require their attention; and indeed for public health experts, who not only see the importance of the built environment in shaping healthy behaviors, but additionally, the role that public space can serve to combat one of the latest public health concerns, social isolation and its consequential physical and mental health effects.

Since Donald Appleyard's study in the 1970s, community severance has become an issue common to most cities in the world, but particularly prevalent in cities in low and middle-income countries. In these cities, increasing urbanization, motorization of transport, and higher incomes are compounded by persistent social and economic inequalities. The result of this process, especially the speed at which it is taking place, is the fragmentation of cities into neighborhoods separated by large road transport infrastructure, where motorized traffic dominates at the expense of pedestrians. The tools we developed are useful to identify community severance in these contexts, but they will need to be adapted to consider factors that are especially relevant to the mobility of pedestrians in those cities, such as personal security; social, cultural, and gender issues; and local perceptions about walking and about car ownership and use.

\section{Acknowledgements}

We gratefully acknowledge the financial support received for the Street Mobility and Network Accessibility research project from the Engineering and Physical Sciences Research Council (EPSRC), Economic and Social Research Council (ESRC) and the Arts and Humanities Research Council (AHRC) (project no. EP/KO37323/1). 


\section{References}

Anciaes, P. (2015) What do we mean by "community severance"? Street Mobility and Network Accessibility Series. Working Paper 4. London: UCL (University College London). http://discovery.ucl.ac.uk/1527807

Anciaes, P., Jones, P. (2016) The influence of motorised traffic on pedestrian flows - new insights using bus stop data. Association for European Transport Papers Repository. https://aetransport.org/en-gb/past-etc-papers/search-all-etc-conferencepapers?search=Anciaes $\&$ abstractld $=4680 \&$ state $=b$

Anciaes, P., Jones, P. (2018) Estimating preferences for different types of pedestrian crossing facilities. Transportation Research F: Psychology and Behavior, 52, 222-237. http://www.sciencedirect.com/science/article/pii/S1369847816303369

Appleyard, D., Gerson M S., Lintell, M. (1981) Livable Streets. University of California Press, London. Appleyard, D., Lintell, M. (1972) The environmental quality of city streets: the residents' viewpoint. Journal of the American Institute of Planners, 38 (2), 84-101.

Asher, L., Aresu, M., Falaschetti, E., Mindell, J S (2012) Most older pedestrians are unable to cross the road in time: a cross sectional study. Age and Aging 41 (5), 690-694.

Barnes, R., Winters, M., Ste-Marie, N., McKay, H., Ashe, M C. (2016). Age and retirement status differences in associations between the built environment and active travel behaviour. Journal of Transport and Health 3(4), 513-522.

Bascom, G W., Christensen, K M. (2017) The impacts of limited transportation access on persons with disabilities' social participation. Journal of Transport and Health 7(B), 227-234.

Berke, E M., Gottlieb, L M., Moudon, A V., Larson, E B. (2007) Protective association between neighborhood walkability and depression in older men. Journal of the American Geriatrics Society, 55 (4), 526-533.

Berkman, L,F., Syme, S L. (1979) Social networks, host resistance, and mortality: a nine-year followup study of Alameda County residents. American Journal of Epidemiology 109(2), 186-204.

Boniface S., Scantlebury R., Watkins S J., Mindell J S. (2015) Health implications of transport: evidence of effects of transport on social interactions. Journal of Transport and Health, 2 (3), 441446.

Bornioli, A., Parkhurst, G., Morgan, PL. (2018) Psychological wellbeing benefits of simulated exposure to five urban settings: an experimental study from the pedestrian's perspective. Journal of Transport and Health. Article in Press, 9:105-116. https://doi.org/10.1016/j.jth.2018.02.003.

Dhanani, A., Tarkhanyan, L., Vaughan, L. (2017) Estimating pedestrian demand for active transport evaluation and planning. Transportation Research Part A: Policy and Practice, 103, 54-69. https://doi.org/10.1016/j.tra.2017.05.020

DoT (Department of Transport) (1983) Manual of Environmental Appraisal. Department of Transport; Assessments, Policy and Methods Division, London 
Duim, E., Lebrão, ML., Antunes, J L F. (2017) Walking speed of older people and pedestrian crossing time. Journal of Transport and Health 5, 70-76.

Giles-Corti, B., Donovan, R J. (2003) Relative influences of individual, social environmental, and physical environmental correlates of walking. American Journal of Public Health 93(9), 1583-1589

Hanna, J., Morton, S., Watkins, S., Mindell, J., Cohen, J. (2011) 'Rethinking streets', Chapter 16 in J S Mindell, J M Cohen and S J Watkins (Eds.) Health on the Move 2, Stockport: Transport and Health Study Group. www.transportandhealth.org.uk/wp-content/uploads/2011/02/HotM2-SectionIV 17Feb11.pdf

Hart, J., Parkhurst, G. (2011) Driven to excess: Impacts of motor vehicles on the quality of life of residents of three streets in Bristol UK. World Transport Policy and Practice 17 (2), 12-30.

Hine, J. (1996) Assessing the impact of traffic on behaviour and perceptions of safety. Journal of Transport Geography 4(3), 179-199.

Holt-Lunstad, J., Smith, T B., Layton, J B. (2010) Social relationships and mortality risk: A metaanalytic review. PLOS Medicine, 7(7): e1000316.

http://journals.plos.org/plosmedicine/article?id=10.1371/journal.pmed.1000316

Hüttenmoser, M. (1995) Children and their living surroundings: empirical investigations into the significance of living surroundings for the everyday life and development of children. Children's Environments 12(4), 403-413.

Jones, P., Roberts, M., Morris, L. (2007) Rediscovering Mixed-Use Streets: The Contribution of Local High Streets to Sustainable Communities. Bristol: Policy Press.

Keller R. C. (2013) Place matters: mortality, space, and urban form in the 2003 Paris heat wave disaster. French Historical Studies, 36 (2), 299-330.

Lassière, A. (1976) The Environmental Evaluation of Transport Plans. Report to the UK Department of Environment, London.

Laverty, A A., Millett, C., Webb, E. (2018) Take up and use of subsidised public transport: evidence from the English Longitudinal Study of Ageing. Journal of Transport and Health, 8, 179-182. https://doi.org/10.1016/j.jth.2018.01.004

Liepmann KK., (1944) The Journey to Work. London: Kegan Paul, Trench, Trubner \& Co. Ltd.

McAndrews, C., \& Marshall, W. (2018). Livable Streets, Livable Arterials? Characteristics of Commercial Arterial Roads Associated With Neighborhood Livability. Journal of the American Planning Association, 84(1), 33-44. https://doi.org/10.1080/01944363.2017.1405737

Mindell, J S., Anciaes, P R., Dhanani, A., Stockton, J., Jones, P., Haklay, M., Groce, N., Scholes, S., Vaughan, L. (2017) Using triangulation to assess a suite of tools to measure community severance. Journal of Transport Geography, 60, 119-129. www.sciencedirect.com/science/article/pii/S0966692316305026

Mindell, J S., Karlsen, S. (2012) Community severance and health: What do we actually know? Journal of Urban Health 89(2), 232-246 
Mouratidis K. (2018) Built environment and social well-being: How does urban form affect social life and personal relationships? Cities 74, 7-20.

Palaiologou G., Vaughan L. (2014) The sociability of the street interface - revisiting West Village, Manhattan., in V Oliveira, P Pinho, L M Batista, T Patatas and C Monteiro (Eds.) Our Common Future in Urban Morphology. Porto: FEUP, 88-102. http://discovery.ucl.ac.uk/1471085

Rothman, L., Buliung, R., To, T., Macarthur, C., Macpherson, A., Howard, A. (2015) Associations between parents' perception of traffic danger, the built environment and walking to school. Journal of Transport and Health 2(3), 327-335.

Sarkar C., Gallacher J., Webster C. (2013) Built environment configuration and change in body mass index: the Caerphilly Prospective Study (CaPS). Health and Place 19, 33-44.

Shaw, B., Watson, B., Frauendienst, B., Redecker, A., Jones, T., Hillman, M. (2013) Children's Independent Mobility: A Comparative Study in England and Germany (1971-2010). London: Policy Studies Institute, www.psi.org.uk/site/publication detail/852

Shaw, L., Lennon, A J., King, M J. (2012) A qualitative investigation of older pedestrian views of influences on their road crossing safety. Presented at the Australasian Road Safety Research, Policing and Education Conference 2012, 4-6 October 2012, Wellington, New Zealand.

https://eprints.qut.edu.au/54489

Smith, J D., Gurney, A. (1992) Community Effects of Traffic Congestion: A Review of the London Assessment Study Data. Contractor Report 314. Crowthorne: Transport Research Laboratory. TfL (Transport for London) (2014) Improving the Health of Londoners - Transport Action Plan. London: Transport for London. http://content.tfl.gov.uk/improving-the-health-of-londonerstransport-action-plan.pdf 